OPEN ACCESS

Edited by:

Youhui Lin

Xiamen University, China

Reviewed by:

Wei Luo,

Donghua University, China Yan Yan Huang,

Nanjing Forestry University, China

*Correspondence:

Jun Ai

imacaj01@163.com

Yong Wang

wangyonglsx@163.com

tThese authors have contributed equally to this work

Specialty section:

This article was submitted to

Nanoscience,

a section of the journal

Frontiers in Chemistry

Received: 05 February 2020

Accepted: 16 March 2020

Published: 07 April 2020

Citation:

Nie F, Ga L, Ai J and Wang Y (2020) Trimetallic PdCuAu Nanoparticles for

Temperature Sensing and

Fluorescence Detection of $\mathrm{H}_{2} \mathrm{O}_{2}$ and

Glucose. Front. Chem. 8:244.

doi: 10.3389/fchem.2020.00244

\section{Trimetallic PdCuAu Nanoparticles for Temperature Sensing and Fluorescence Detection of $\mathrm{H}_{2} \mathrm{O}_{2}$ and Glucose}

\author{
Furong $\mathrm{Nie}^{1 \dagger}$, $\mathrm{Lu} \mathrm{Ga}^{2 \dagger}$, Jun $\mathrm{Ai}^{1 *}$ and Yong Wang ${ }^{3 *}$ \\ ${ }^{1}$ College of Chemistry and Enviromental Science, Inner Mongolia Normal University, Hohhot, China, ${ }^{2}$ College of Pharmacy, \\ Inner Mongolia Medical University, Hohhot, China, ${ }^{3}$ College of Geographical Science, Inner Mongolia Normal University, \\ Hohhot, China
}

The design of palladium-based nanostructures has good prospects in various applications. This paper reports a simple one-step synthesis method of PdCuAu nanoparticles (PdCuAu NPs) prepared directly in aqueous solution. PdCuAu NPs have attracted much attention owing to their unique synergistic electronic effect, optical and catalytic performance. As temperature sensor, PdCuAu NPs are sensitive to the fluorescence intensity change in the temperature range of $4-95^{\circ} \mathrm{C}$, which is due to its unique optical properties. The prepared PdCuAu NPs have excellent catalytic performance for peroxidase-like enzymes. It can catalyze TMB rapidly in the presence of hydrogen peroxide and oxidize it to visible blue product (oxTMB). Based on its unique peroxidase-like properties, this study used PdCuAu NPs colorimetric platform detection of hydrogen peroxide and glucose. The linear ranges of hydrogen peroxide and glucose were $0.1-300 \mu \mathrm{M}$ and $0.5-500 \mu \mathrm{M}$, respectively, and the detection limits (LOD) were 5 and $25 \mathrm{nM}$, respectively. This simple and rapid method provides a good prospect for the detection of $\mathrm{H}_{2} \mathrm{O}_{2}$ and glucose in practical applications.

Keywords: trimetallic alloyed nanoparticles, temperature-sensitive, sensor, peroxidase-like activity, colorimetric system

In recent years, the research on the preparation and application of nano-device mainly focuses on the preparation and application of polymetallic nanomaterials (Dubau et al., 2015; Xia et al., 2015; Luo and Shen, 2017; Yang et al., 2017; Tang et al., 2018). Because of their unique physical and chemical properties, polymetallic nanomaterials have been widely used in optics, chemical reactions, fuel cells, sensors and catalysts (Huang et al., 2014; Khan et al., 2015; Tang et al., 2018; Wang et al., 2018). At present, Pt-based nanomaterials are the most widely used catalysts because of their high catalytic activity in cathodic and anodic reactions (Khan et al., 2015; Wang et al., 2018). Consequently, tri-metallic Pt-based alloys for instance Pt-Ni-Cu (Tang et al., 2018), Pt-Ni-Co (Huang et al., 2014; Sriphathoorat et al., 2016), Pt-Pd-Cu (Yin et al., 2012; Tian et al., 2017), Pt-Pd-Co (Cho et al., 2014; Song et al., 2015), Pt-Fe-Ni (Li and Chan, 2013), Pt-Fe-Co (Hwang et al., 2011), and Pt-Pd-Au (Li et al., 2018) aroused the attention of many studies. However, due to the low cost and high catalytic activity of Pd-based catalysts, there are few studies on Pd-based catalysts (Guo et al., 2014; Jiang et al., 2015; Xu et al., 2015; Yousaf et al., 2017a), therefore, Pdbased catalysts are the most promising substitute for Pt-based catalysts (Xu et al., 2015; Yousaf et al., 2017a; Wang et al., 2018). Many researchers have done a lot of work on Pd-based catalysts 
to improve the catalytic performance of palladium catalysts (Wang X. et al., 2015; Xue et al., 2017; Yousaf et al., 2017b). Wang et al. reported a very simple method to synthesize trimetal PdCuAu nanoparticles (NPs) with branched structure, so the PdCuAu NPs have excellent catalytic performance, durability and methanol oxidation resistance (Wang et al., 2018). Huang et al. proposed to prepare an ordered $\mathrm{PdCu}$ based NPs (PdCuCo, and PdCuNi) by colloidal chemistry. $\mathrm{PdCuCo}$ NPs have excellent stability and activity in redox reaction because of their intermetallic phase and composition advantages (Jiang et al., 2016). Yang's group reported that the $\mathrm{CuPd}$ alloy with controllable shape was preparation of oleylamine by electric substitution reaction. $\mathrm{Put} \mathrm{Cu}$ in $\mathrm{Pd}$ could reduce the bond intensity among the intermediate and palladium, cause the enhancement of lattice shrinkage, thus improving the electrocatalytic performance of redox reaction (Chen D. et al., 2017). Consequently, the Pd-based alloy nanomaterials are considered as a promising catalyst with enhanced catalytic performance. However, Pd-based alloy nanomaterials are seldom used in the field of sensors. In this paper, the application of Pd-based alloy nanomaterials in sensors is studied.

In recent years, thermosensitive materials have shown significant activity due to their possible applications in nanoscale temperature measurement (Zhou et al., 2018). Though, many temperature sensitive materials have a single signal response, and the fluorescence stability and contrast are poor. Dong group studied a novel dual fluorescence temperature sensor based on DNA- template Ag NCs. It has two fluorescence peaks and can be used for sensitive detection of temperature changes from 15 to $45^{\circ} \mathrm{C}$ (Zhou et al., 2018). Oemrawsingh studied that the single emitter fluorescence of Ag NCs increased 5-fold when the temperature dropped from 295 to $1.7 \mathrm{~K}$ (Oemrawsingh et al., 2012). Chen et al. reported a hairpin-like Ag NCs with DNA template. The Ag NCs exhibited reversible fluorescence properties between 25 and $66^{\circ} \mathrm{C}$ due to the loosening and compacting of the four-stranded template structure (Zhao et al., 2015). A one-step synthesis method for prepared high fluorescence bimetallic $\mathrm{Cu}-\mathrm{Au}$ nanoclusters ( $\mathrm{Cu} / \mathrm{Au} \mathrm{BNCs}$ ) was proposed by $\mathrm{Ai}$ group. The fluorescence signals of $\mathrm{Cu} / \mathrm{Au}$ BNCs exhibited reversible response and good sensitivity in the temperature range of $20-70^{\circ} \mathrm{C}$ (Nie et al., 2018). The Pdbased alloy nanomaterials have been successfully applied to temperature sensing in this paper.

Peroxidases are an important biocatalyst in organism, which can catalyze many kinds of biochemical reactions effectively, for example, they can deactivate toxic substances, oxidize fatty acids, regulate oxygen concentration and so on. Because of their incredible efficiency and high substrate specificity, they are of great importance in diagnosis and analysis (Guo et al., 2018). In recent years, nanozymes have attracted much attention due to their endogenous mimic enzymes similar to natural enzymes, it can catalyze substrate reaction (Yan et al., 2018). Compared with natural enzymes, nano-enzyme production process is simple and economical, and it has excellent robustness and stability. In the past, researchers have found that various nanomaterials possess catalytic properties of peroxidase-like enzymes. Among many nanomaterials, inorganic nanomaterials have also attracted attention, including metal oxides $\mathrm{V}_{2} \mathrm{O}_{3}$ (Han et al., 2015), $\mathrm{NiO}$ (Liu et al., 2015), $\mathrm{CuO}$ (Wang et al., 2013; Chen M. et al., 2017), $\mathrm{CeO}_{2}$ (Liu et al., 2017a; Sun et al., 2017; Ge et al., 2019; Yang et al., 2019), and sulfides ZnS

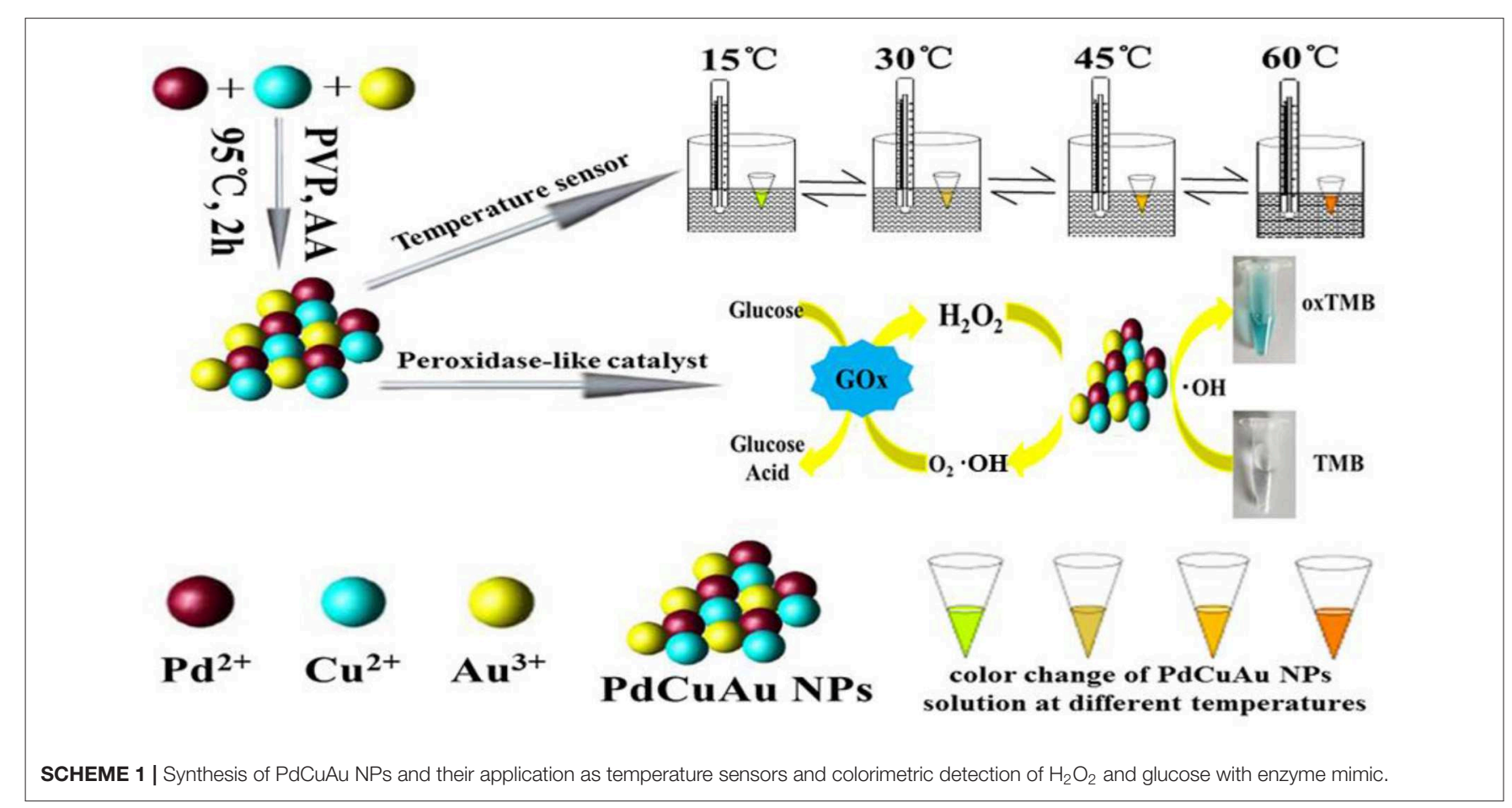


(Liu et al., 2017b), CdS (Liu et al., 2014), CuS (Zhang et al., 2017a) etc. Compared to the analytical methods including electrochemistry (Niu et al., 2013), fluorescence (Hu et al., 2014; Shan et al., 2014), chemiluminescence (Luo et al., 2015), mass spectroscopy (Chen et al., 2012), colorimetric detection method has the advantages of low cost, high selectivity and strong practicability, and is favored by researchers. In addition, because the color change of the substrate does not require any complicated instrument, it is easy to observe with the naked eye, so it has a wide range of applications in many fields (Ding et al., 2017).

Herein, we report a one-step synthesis of trimetallic $\mathrm{PdCuAu}$ nanoparticles (NPs) in aqueous phase without any intermediates. The sensitive fluorescence signals of PdCuAu NPs are reversible and recyclable in the range of $4-95^{\circ} \mathrm{C}$. The prepared $\mathrm{PdCuAu}$ NPs show superior catalytic activity and sensitive in answer to the chromogenic substrate TMB, it can catalyze TMB in the presence of $\mathrm{H}_{2} \mathrm{O}_{2}$. So, the flow chart for the preparation of PdCuAu NPs and the application of PdCuAu NPs as temperature sensors and peroxidase-like enzymatic reactions are described in Scheme 1.

\section{RESULTS AND DISCUSSION}

\section{Optimization and Characterization of the Synthesis Conditions of PdCuAu NPs}

This is a very simple and easy to operate synthesis process: take $355 \mu \mathrm{L} \mathrm{H}_{2} \mathrm{PdCl}_{4}$ solution $(56.4 \mathrm{~mm}), 1 \mathrm{ml} \mathrm{Cu}\left(\mathrm{NO}_{3}\right)_{2}$ solution $(0.1 \mathrm{M})$, and $412 \mu \mathrm{L} \mathrm{HAuCl}_{4}$ solution $(48.6 \mathrm{mM})$ and mix them evenly, and then add $500 \mu \mathrm{L} \mathrm{HCl}$ (10\%), $100 \mathrm{mg}$ $\mathrm{KBr}$ and $50 \mathrm{mg} \mathrm{PVP}$ into them after ultrasonic degradation, and then add $2 \mathrm{ml}$ ascorbic acid (AA) (0.1 M) After heating the mixed solution in a water bath at $95^{\circ} \mathrm{C}$ and stirring for $2 \mathrm{~h}$, the primary product PdCuAu NPs is obtained after natural cooling. The primary product PdCuAu NPs is centrifuged at a centrifugal rate of $5,000 \mathrm{rpm}$ for $15 \mathrm{~min}$, and then the supernatant and sediment are centrifuged. The purified final product is stored in 4 In the environment of ${ }^{\circ} \mathrm{C}$, it is used for the following analysis and characterization experiments, i.e., ultraviolet spectrum analysis, fluorescence spectrum analysis, transmission electron microscopy test, infrared spectrum test, XRD and XPS test.

The reaction mixture was heated for $2 \mathrm{~h}$ by simple heat treatment at $95^{\circ} \mathrm{C}$ in a water bath. The obtained tri-metallic $\mathrm{PdCuAu}$ NPs were canary yellow in water phase (see Figure 1, inset, left). The pale blue fluorescence was observed in the PdCuAu NPs solution under UV illumination at $365 \mathrm{~nm}$ (see Figure 1, inset, right), and the PdCuAu NPs are excited at $358 \mathrm{~nm}$ and emit at $443 \mathrm{~nm}$. Typical magnification transmission electron microscopy (TEM) and high-resolution TEM (HRTEM) images of the as-prepared product are shown in Figure 2. Their particles are distributed between 10 and $25 \mathrm{~nm}$, with an average particle size of $13 \mathrm{~nm}$ (see Figures 2a,b). Since the measured lattice distance of PdCuAu NPs are $0.2106 \mathrm{~nm}$, the lattice fringes of $\mathrm{PdCuAu}$ NPs are assigned to the (111) plane of the Fourier filtering image (see Figures 2c,d).

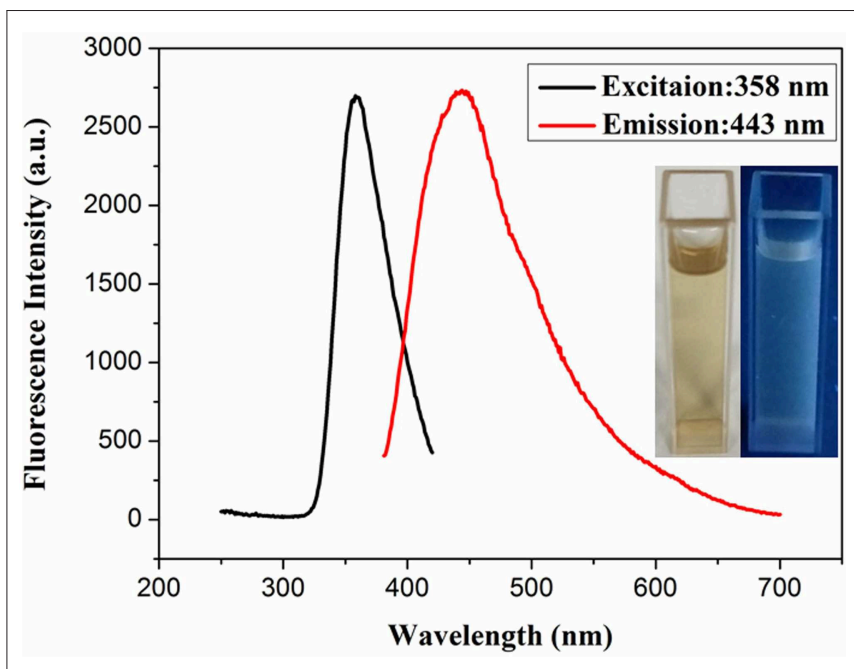

FIGURE 1 | Fluorescence spectra of PdCuAu NPs. [Insets, the left panel was shown in visible light, and the right was viewed under UV radiation $(365 \mathrm{~nm})$ ].

The crystal structure of PdCuAu NPs is measured by XRD. As shown in Figure 3A, the representative diffraction peaks at 38.18, $40.12,44.39,64.58$, and $77.55^{\circ}$ are assigned to the (111), (111), (200), (220), and (311) planes of PdCuAu NPs, respectively. The peak positions of $\mathrm{PdCuAu}$ NPs are all situated between the homologous peaks of pure Au (JCPDS card no. 04-0784) and Pd (JCPDS card no. 46-1043), which confirm the formation of PdCuAu alloy. Both the HRTEM pattern (see Figures 2c,d) and from the XRD analysis (see Figure 3A), we can see that PdCuAu NPs show good crystallinity. The surface properties of PVP and $\mathrm{CuAu}, \mathrm{PdAu}, \mathrm{PdCu}$, and PdCuAu NPs were characterized by FT-IR spectrometer. Exactly as shown in Figure 3B, the peak at 3,445 and $1,075 \mathrm{~cm}^{-1}$ were the characteristic absorption peak of the N-H stretching vibration of PVP, $2,955 \mathrm{~cm}^{-1}$ for the $\mathrm{C}-\mathrm{H}$ stretching vibration of aromatic ring, $2,141 \mathrm{~cm}^{-1}$ for the stretching vibration of $\mathrm{C}-\mathrm{H}$ outside the surface, 1,660 and $1,441 \mathrm{~cm}^{-1}$ for the $\mathrm{C}-\mathrm{C}$ stretching vibration of aromatic ring skeleton, $1,294 \mathrm{~cm}^{-1}$ for the $\mathrm{C}-\mathrm{N}$ stretching vibration of aromatic hydrocarbons. By comparison, the peak at 2,955 and 2,141 $\mathrm{cm}^{-1}$ disappeared in PdCuAu NPs, it indicates the breakup of $\mathrm{C}-\mathrm{H}$ bond and the formation of new copper compounds. As determined by the TEM-EDS analysis, the atomic percentage of $\mathrm{Pd}$ in these nanocrystals is $42.14 \%$ and $\mathrm{Au}$ in these nanocrystals is $55.62 \%$, the atomic ratio of $\mathrm{Pd} / \mathrm{Au}$ in the as-prepared sample is $\sim 1: 1$ (see Figure S1). Among the TEM-EDS pattern (see Figure S1), FT-IR pattern (see Figure 3B) and XPS pattern (see Figure 3C) show that the formation of copper compounds. The surface chemical composition and valence state of PdCuAu NPs were further studied by X-ray photoelectron spectroscopy (XPS). As shown in Figure 3C, the Pd 3d region of the sample can be divided into two pairs of doublets. Two $\mathrm{Pd} 3 \mathrm{~d}$ peaks are located at 335.6 and $340.9 \mathrm{eV}$, corresponding to the $\mathrm{Pd} 3 \mathrm{~d}_{5 / 2}$ and $\mathrm{Pd} 3 \mathrm{~d}_{3 / 2}$ states of metallic $\mathrm{Pd}$, respectively. The binding energies at 932.4 and $952.3 \mathrm{eV}$ correspond to $\mathrm{Cu} 2 \mathrm{p}_{3 / 2}$ and $\mathrm{Cu}$ $2 \mathrm{p}_{1 / 2}$ by fitting these peaks, which are assigned to $\mathrm{Cu}^{+}$and 


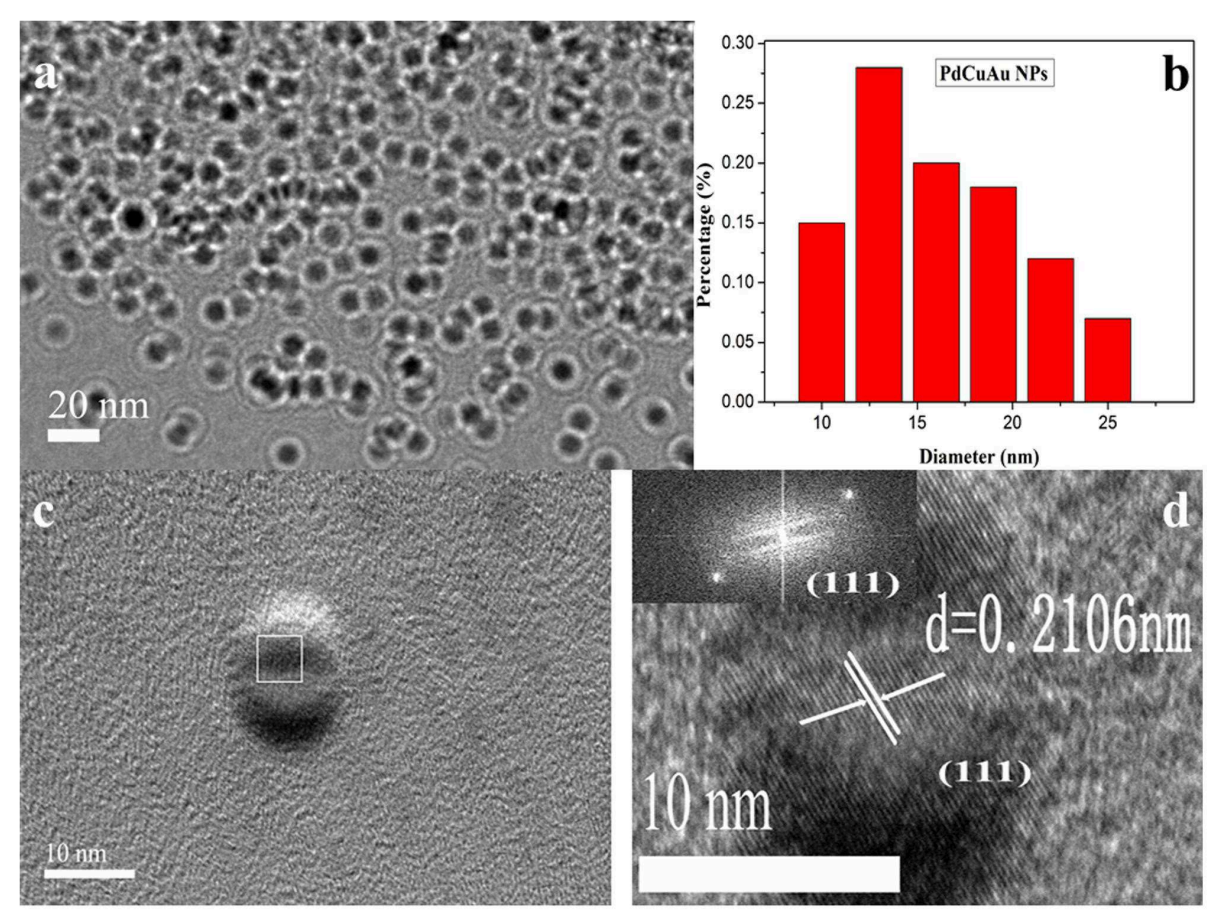

FIGURE 2 | (a) TEM images of the PdCuAu NPs. (b) The size distribution of PdCuAu NPs. (c) HRTEM image of the PdCuAu NPs. (d) The lattice fringes in the square area in (c) and the inset displays the corresponding FFT pattern.

$\mathrm{Cu}^{2+}$, respectively. Similarly, the peaks at 83.8 and $87.5 \mathrm{eV}$ are attributed to $\mathrm{Au} 4 \mathrm{f}_{7 / 2}$ and $\mathrm{Au} 4 \mathrm{f}_{5 / 2}$ by fitting these peaks, it is proved that $\mathrm{Au}^{3+}$ is reduced to $\mathrm{Au}^{0}$. Therefore, $\mathrm{Pd}$ and $\mathrm{Au}$ are the main species of PdCuAu NPs, so PdCuAu NPs have the potential to be effective catalysts.

Some controlled contrast experiments were carried out to explore the influencing factors in the process of synthesizing $\mathrm{PdCuAu}$ NPs. $\mathrm{Pd} / \mathrm{Cu} / \mathrm{Au}$ molar ratio, $(\mathrm{Pd} / \mathrm{Cu} / \mathrm{Au}=1: 1: 1$, 1:2:1, $1: 1: 2 \mathrm{~mol} / \mathrm{mol}$ ) were researched and the corresponding fluorescence spectra were shown in Figure S2A. The optimal $\mathrm{Pd} / \mathrm{Cu} / \mathrm{Au}$ molar ratio is $1: 5: 1$, the fluorescence intensity of PdCuAu NPs (1:5:1) are the strongest (see Figure S2B) and it can also be obtained from the TEM image that the dispersion of PdCuAu NPs (1:5:1) are the best and the particle size is uniformity (see Figure S3). Figure S4 showed that the PdCuAu NPs exhibited the maximum fluorescence intensity under a water bath at $95^{\circ} \mathrm{C}$ for $2 \mathrm{~h}$. If the time is too short, the temperature is too low, and the reaction may not be complete, resulting in agglomeration of $\mathrm{PdCuAu}$ NPs (see Figures S5, S6). By comparison, the fluorescence intensity of $\mathrm{CuAu}, \mathrm{PdAu}$, $\mathrm{PdCu}$ NPs are weak and the products tended to aggregate (see Figures S7A, S8). If there is no $\mathrm{Br}^{-}$in the reaction, irregular and agglomerated PdCuAu NPs can be obtained, which fully shows that $\mathrm{Br}$ - plays a key role in the formation of $\mathrm{PdCuAu}$ NPs (see Figures S7B, S9). In addition, $\mathrm{Cu}^{2+}$ plays a very important role in controlling the morphology and fluorescence of PdCuAu NPs. For bimetallic PdAu, if $\mathrm{Cu}^{2+}$ is not added, the resulting nanoparticles are irregular, and these nanoparticles were exhibited weak fluorescence intensity (see Figures S7B, S9). When PVP is not added in the preparation process, many large particles will be obtained and serious agglomeration will occur. Copolymer PVP as a template can effectively improve the dispersion of nucleated nanoparticles and reduce the possibility of agglomeration (see Figures S6B, S8). Moreover, we also found that $\mathrm{HCl}$ has a significant effect on the morphology and fluorescence of PdCuAu NPs. In the absence of $\mathrm{HCl}$, agglomerated and irregular nanoparticles were formed due to their rapid reduction kinetics (see Figures S7B,C, S10). Because $\mathrm{HCl}$ can reduce the reduction ability of ascorbic acid, the reduction rate of metal salt precursors in the reactants will be reduced when $\mathrm{HCl}$ is added to the reaction system. According to the above control experiments, we synthesized the PdCuAu NPs in a water bath at $95^{\circ} \mathrm{C}$ for $2 \mathrm{~h}$ with a molar ratio of $\mathrm{Pd} / \mathrm{Cu} / \mathrm{Au}$ equal to 1:5:1. The optical stability of PdCuAu NPs was further studied by fluorescence spectroscopy, as shown in Figure S11. With the passage of time, the fluorescence intensity of PdCuAu NPs was monitored periodically by fluorescence characterization. The results showed that the fluorescence intensity of PdCuAu NPs changed little within 45 days. Therefore, PdCuAu NPs have good stability.

\section{Fluorescence Detection for Temperature Sensor}

In recent years, there is little research on temperature sensors, and the PdCuAu NPs prepared in this paper have a good response by fluorescence detection in a wide temperature 


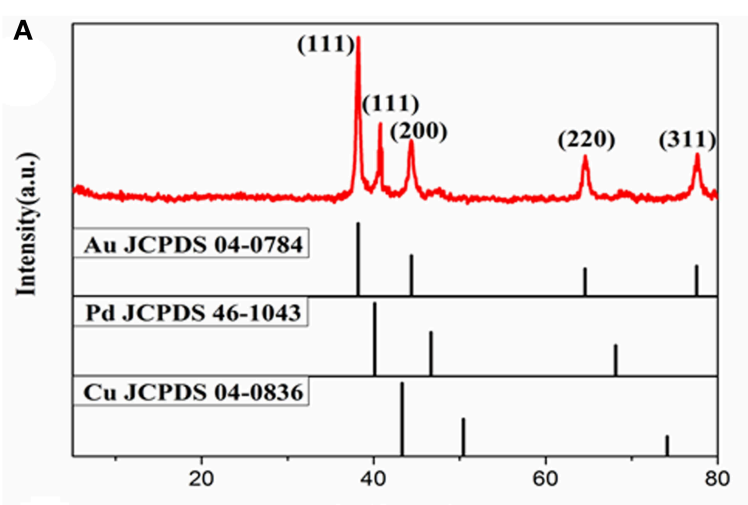

C

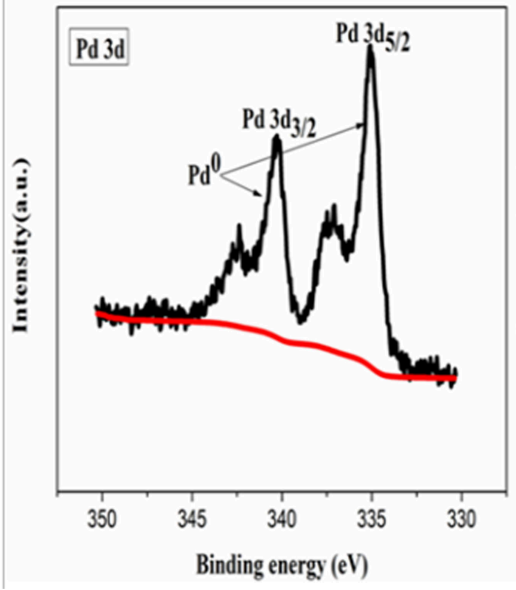

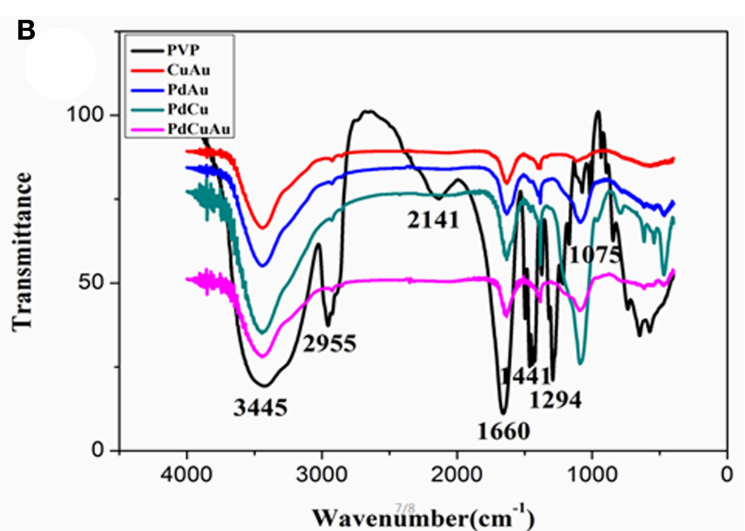
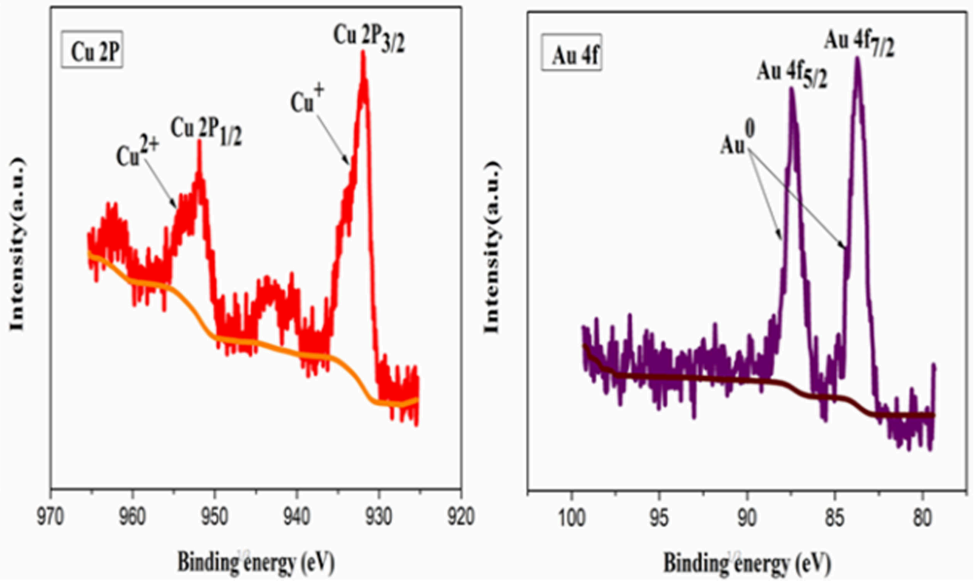

FIGURE 3 | (A) XRD pattern of PdCuAu NPs, the standard patterns of pure Au (JCPDS card no. 04-0784), Pd (JCPDS card no. 46-1043) and Cu (JCPDS card no. 04-0836) are shown for comparison. (B) FT-IR spectra of pure PVP, CuAu, PdAu, PdCu, and PdCuAu NPs. (C) X-ray photoelectron spectroscopy spectra of Pd 3d, $\mathrm{Cu} 2 \mathrm{p}$, and $\mathrm{Au} 4 \mathrm{f}$ of the as-prepared PdCuAu NPs.

range of $4-95^{\circ} \mathrm{C}$. Therefore, $\mathrm{PdCuAu}$ NPs has potential application as a temperature sensor. As shown in Figure 4A. The fluorescence intensity of $\mathrm{PdCuAu}$ NPs decreased with the increase of temperature, but the emission peak position of PdCuAu NPs did not shift in the temperature range studied. The reason for this phenomenon may be due to the thermal motion of the non-radiative process, that is to say, the frequency of collision and the rate of non-radiative transition of the molecule will increase at high temperature, thus reducing the emission intensity of the excited state (Wang C. et al., 2015; Wang et al., 2016; Jiang et al., 2017). In the temperature range of $4-95^{\circ} \mathrm{C}$, the linear relationship between fluorescence intensity and temperature is illustrated in Figure 4B, the linear equation was $F=-29.03 \mathrm{~T}+3,204$ $(R=0.9988)$. Furthermore, the recyclability and reversibility of resultant PdCuAu NPs based on a fluorescent thermometer were also investigated. As revealed in Figure 4C, the response of PdCuAu NPs to temperature is reversible. After heating and cooling, the reversible process can repeat at least eight cycles without obvious change of fluorescence signal. The results show that $\mathrm{PdCuAu}$ NPs have excellent reutilization in response to temperature changes.

\section{Peroxidase-Like Catalytic Activity of PdCuAu NPs}

In order to explore the catalytic activity of PdCuAu NPs, the peroxidase activity of $\mathrm{PdCuAu}$ NPs was studied with TMB as chromogenic substrate. The top of Figure 5B point out the color changes in different environments. When there is $\mathrm{H}_{2} \mathrm{O}_{2}$ in the reaction system, PdCuAu NPs can catalyze the oxidation of TMB to produce typical blue products visible to the naked eye, indicating that PdCuAu NPs have the peroxidase activity. Like natural peroxidase HRP, temperature and $\mathrm{pH}$ are important factors affecting the catalytic activity of PdCuAu NPs. The peroxidase-like activity of $\mathrm{PdCuAu}$ NPs at different $\mathrm{pH}$ environments $(3.5-6.0)$ and temperatures $\left(25-60^{\circ} \mathrm{C}\right)$ was studied (see Figure S12). The catalytic activity of PdCuAu NPs increases with the increase of $\mathrm{pH}$. When the $\mathrm{pH}$ is equal to 5.0, the catalytic activity of PdCuAu NPs reaches the maximum. If the $\mathrm{pH}<5.0$, the catalytic activity of PdCuAu NPs decreases, this 


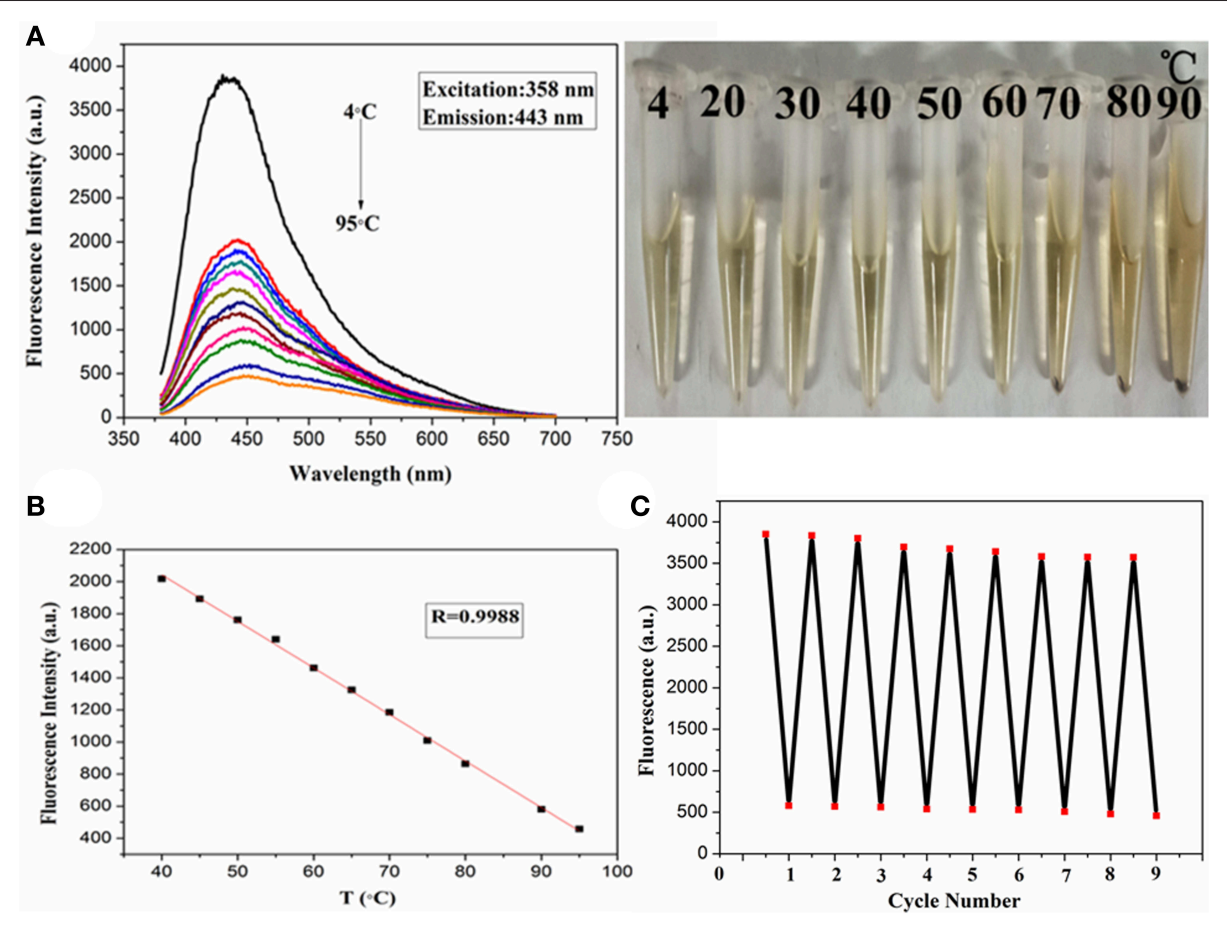

FIGURE 4 | (A) Fluorescence spectra of PdCuAu NPs with temperature ranging from 4 to $95^{\circ} \mathrm{C}$. (B) The linear relationship between changes of temperature and fluorescence intensity. (C) The fluorescence response of eight cycles at $4-95^{\circ} \mathrm{C}$.

is because $\mathrm{pH}<2$ easily produces yellow diimine, and $\mathrm{pH}>$ 5 will accelerate the decomposition of hydrogen peroxide (see Figure S12A). Besides, the effect of temperature on PdCuAu NPs also discussed, because temperature can accelerate enzymatic reaction, but too high temperature will lead to inactivation of enzymatic reaction, so there is an optimum temperature for enzymatic reaction. The optimum temperature for enzymatic reaction in this study is $40^{\circ} \mathrm{C}$ (see Figure S12B). For the comparative experiment of catalytic activity of PdCuAu NPs, the steady-state kinetics method was used in this experiment. A typical Michaelis-Menten curve was obtained by controlling the concentration of one peroxidase substrate unchanged and then changing the concentration of another peroxidase substrate (see Figures S13A-D). In Table S1, we can see the kinetic parameters of enzymes derived from Lineweaver-Burk. As everyone knows that $\mathrm{K}_{\mathrm{m}}$ can express the affinity of specific enzymes to substrates. When the $K_{m}$ value is small, the affinity between enzyme and substrate is strong, whereas a weaker affinity. It can be drawn from Table S1, the $\mathrm{K}_{\mathrm{m}}$ value of $\mathrm{PdCuAu}$ NPs with $\mathrm{H}_{2} \mathrm{O}_{2}$ as the substrate was low. On the one hand, the $\mathrm{K}_{\mathrm{m}}$ value of PdCuAu NPs with TMB as substrate was low, which indicates that PdCuAu NPs have strong affinity with TMB. In addition, the $\mathrm{K}_{\mathrm{m}}$ of PdCuAu NPs as shown in Table S1 is lower than that of other reported materials. Therefore, in subsequent experiments, we chose $\mathrm{pH}=5.0$ and temperature was $40^{\circ} \mathrm{C}$ as the best reaction conditions. Because PdCuAu NPs have excellent catalytic performance, we designed a convenient, rapid and direct colorimetric method for the detection of $\mathrm{H}_{2} \mathrm{O}_{2}$.
Figures $\mathbf{5 A}, \mathbf{B}$ showed that the absorbance of TMB is positively correlated with the concentration of $\mathrm{H}_{2} \mathrm{O}_{2}$ at $652 \mathrm{~nm}$ with the $R$ $=0.9975$. The linear regression equation obtained was $A=6.95$ $\times 10^{-3}\left[\mathrm{H}_{2} \mathrm{O}_{2}\right]+0.04713$ with a linear range of $0.1-300 \mu \mathrm{M}$. When the signal-to-noise ratio $(\mathrm{S} / \mathrm{N})$ is 3 , the calculated LOD $=5 \mathrm{nM}$, which is much lower than the detection limit of other reported nanomaterials, for instance $\mathrm{Co}_{3} \mathrm{O}_{4}$ NPs (Ding et al., 2017) GQDs/CuO nanocomposites (Zhang et al., 2017b). GOx can catalyze the oxidation of glucose to produce $\mathrm{H}_{2} \mathrm{O}_{2}$, that is to say, PdCuAu NPs as a peroxidase coupled with GOx to simulate the above-mentioned TMB- $\mathrm{H}_{2} \mathrm{O}_{2}$ system to indirectly detect glucose (see Scheme 1). As shown in Figure 6A, when the maximum absorption wavelength is $652 \mathrm{~nm}$, the absorbance increases with the increase of glucose concentration. The linear range of the standard curve of absorbance changes with glucose concentration is $0.5-500 \mu \mathrm{M}$ with the $R=0.9928$ and the linear regression equation obtained was $A=6.512 \times 10^{-4}$ [glucose] +0.04484 . When the signal-to-noise ratio $(\mathrm{S} / \mathrm{N})$ is 3 , the LOD of this method is as low as $25 \mathrm{nM}$, which is much lower than the LOD reported in the previous literature, such as Pt nanoclusters (Jin et al., 2017), $\mathrm{NiCo}_{2} \mathrm{O}_{4} / 3 \mathrm{DGF}$ (Wu et al., 2015). The color change of different concentration of glucose solution can be observed with eyes very clearly (top of Figure 6B). PdCuAu NPs detection system shows a wide linear range and it has excellent sensitivity to glucose. The selectivity of glucose/GOx/PdCuAu NPs/TMB system was also studied. under the same conditions, we selected several other sugars (fructose, sucrose, lactose and maltose) for the comparative 
A

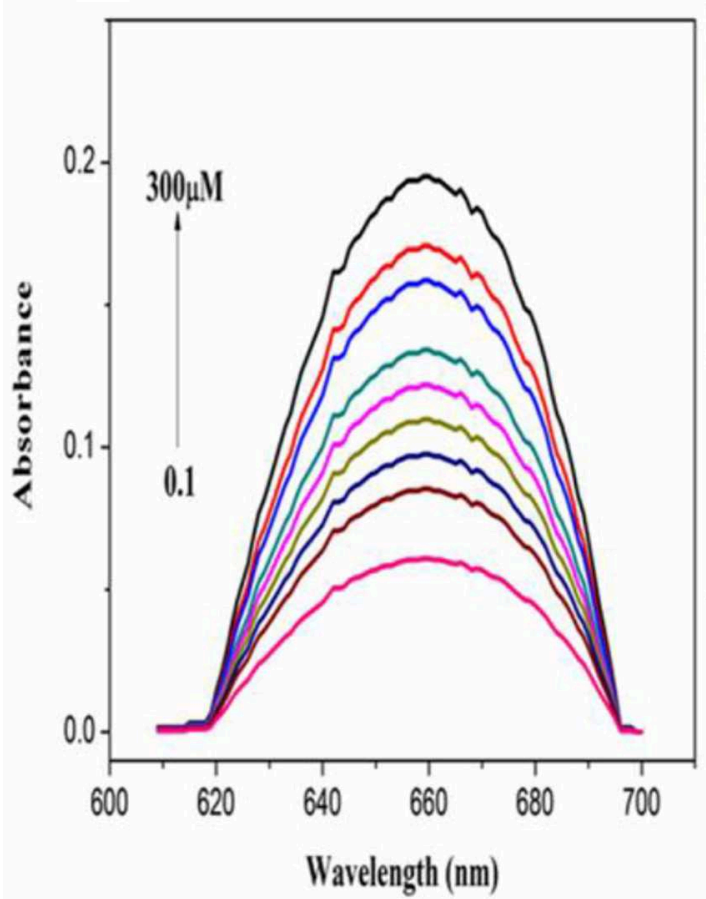

B
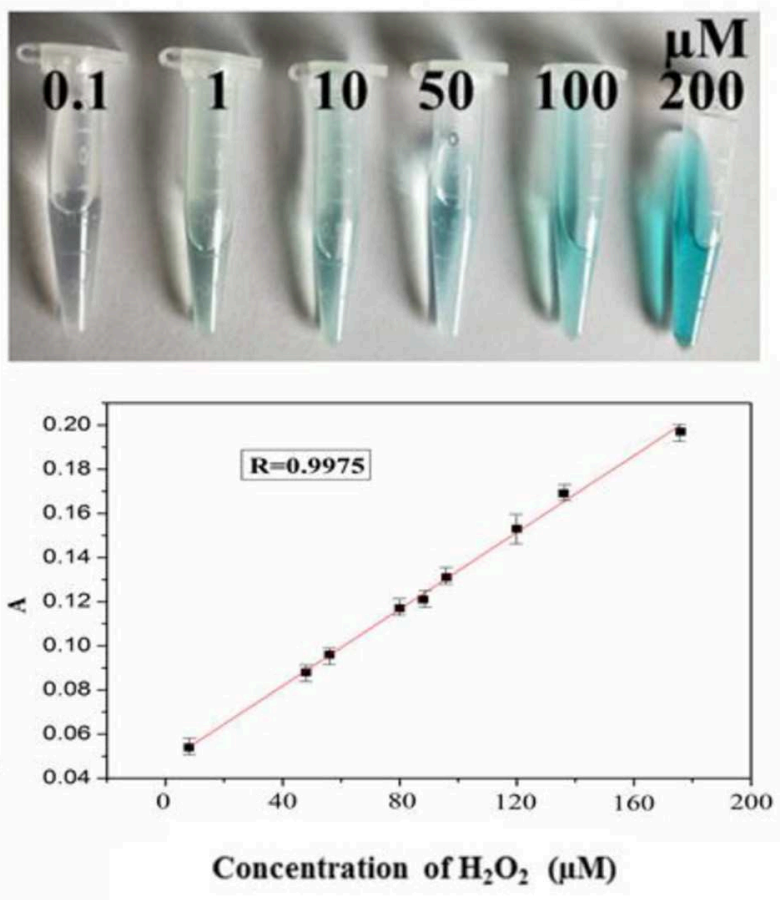

FIGURE 5 | (A) The absorption spectra of PdCuAu NPs and TMB system upon adding different concentrations of $\mathrm{H}_{2} \mathrm{O}_{2}(0.1-300 \mu M$, from bottom to top). (B) The corresponding linear calibration plots for $\mathrm{H}_{2} \mathrm{O}_{2}$, top: the corresponding color changes.

A

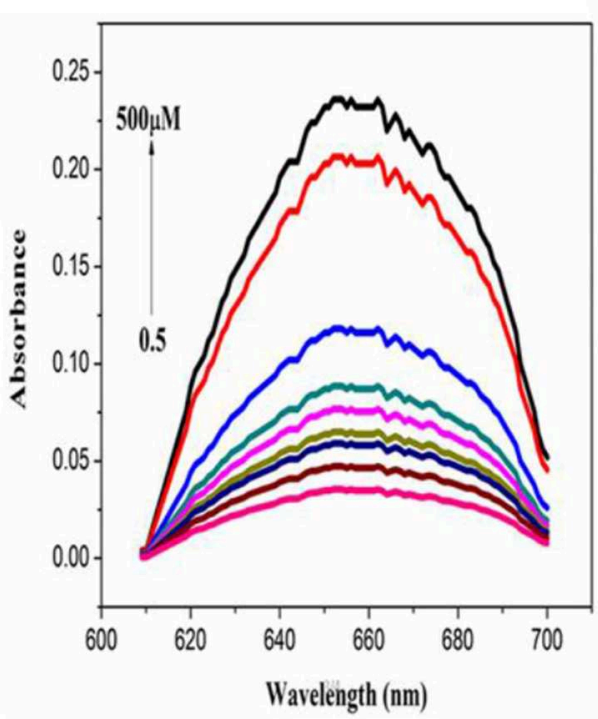

B
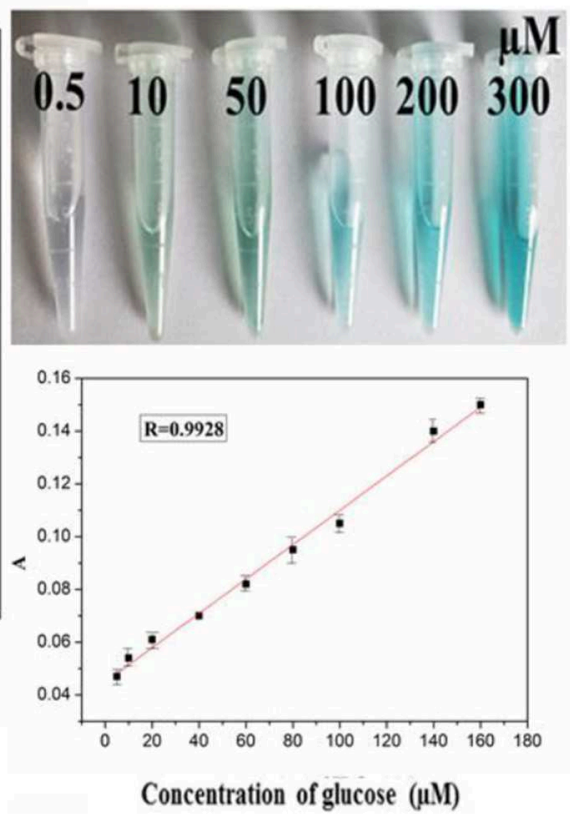

FIGURE 6 | (A) The absorption spectra of PdCuAu NPs and TMB system upon adding different concentrations of glucose (0.5-500 $\mu$ M, from bottom to top). (B) The corresponding linear calibration plots for glucose, top: the corresponding color changes. 
experiment. We can get it from Figure S14, glucose analogs had little interference in the detection of glucose. This indicates that the system of glucose/GOx/PdCuAu NPs/TMB has high selectivity for the detection of glucose due to the specificity of GOx. Therefore, glucose sensor based on PdCuAu NPs can be established successfully.

\section{CONCLUSIONS}

In conclusion, the synthesis of polymetallic nanomaterials requires very stringent conditions. This is because it is difficult to control the reduction and nucleation process of metal salt precursors in the reactants, so we successfully prepared $\mathrm{PdCuAu}$ NPs by a very simple one-pot synthesis method in this experiment. The method is simple in operation, mild in reaction conditions and does not require multi-step synthesis. Moreover, the growth mechanism of PdCuAu NPs was also studied through a series of control experiments. The resultant PdCuAu NPs show remarkable features including fluorescence properties and superior catalytic activity. The research shows that it has good sensitivity to temperature change and good linear relationship, so it can be used in thermal imaging of biological environment. Additionally, the prepared PdCuAu NPs have peroxidase-like catalytic properties. It can catalyze $\mathrm{TMB}$ in the presence of $\mathrm{H}_{2} \mathrm{O}_{2}$ to produce color reaction, and the whole experimental process only takes $10 \mathrm{~min}$. Therefore, we constructed a colorimetric sensor with high selectivity and rapid response using PdCuAu NPs as mimetic enzymes, and applied it to the detection of $\mathrm{H}_{2} \mathrm{O}_{2}$ and glucose. The synthesized PdCuAu NPs have excellent temperature sensors and catalytic performance for peroxidaselike enzymes. The PdCuAu NPs have good stability. However,

\section{REFERENCES}

Chen, D., Sun, P., Liu, H., and Yang, J. (2017). Bimetallic Cu-Pd alloy multipods and their highly electrocatalytic performance for formic acid oxidation and oxygen reduction. J. Mater. Chem. A 5, 4421-4429. doi: 10.1039/C6TA $10476 \mathrm{~B}$

Chen, M., Ding, Y., Gao, Y., Zhu, X., Wang, P., Shi, Z., et al. (2017). $\mathrm{N}, \mathrm{N}^{\prime}$-di-caboxy methyl perylene diimides (PDI) functionalized $\mathrm{CuO}$ nanocomposites with enhanced peroxidase-like activity and their application in visual biosensing of $\mathrm{H}_{2} \mathrm{O}_{2}$ and glucose. RSC $A d v .7,25220-25228$. doi: 10.1039/C7RA04463A

Chen, R., Xu, W., Xiong, C., Zhou, X., Xiong, S., Nie, Z., et al. (2012). High-salttolerance matrix for facile detection of glucose in rat brain Microdialysates by MALDI mass spectrometry. Anal. Chem. 84, 465-469. doi: 10.1021/ac202438a

Cho, Y.-H., Kim, O.-H., Chung, D. Y., Choe, H., Cho, Y.-H., and Sung, Y.-E. (2014). PtPdCo ternary electrocatalyst for methanol tolerant oxygen reduction reaction in direct methanol fuel cell. Appl. Catal. B Environ. 154-155, 309-315. doi: 10.1016/j.apcatb.2014.02.016

Ding, Y., Chen, M., Wu, K., Chen, M., Sun, L., Liu, Z., et al. (2017). Highperformance peroxidase mimics for rapid colorimetric detection of $\mathrm{H}_{2} \mathrm{O}_{2}$ and glucose derived from perylene diimides functionalized $\mathrm{Co}_{3} \mathrm{O}_{4}$ nanoparticles. Mater. Sci. Eng. C 80, 558-565. doi: 10.1016/j.msec.2017.06.020

Dubau, L., Asset, T., Chattot, R., Bonnaud, C., Vanpeene, V., Nelayah, J., et al. (2015). Tuning the performance and the stability of porous hollow PtNi/C nanostructures for the oxygen reduction reaction. ACS Catal. 5, 5333-5341. doi: $10.1021 /$ acscatal.5b01248
It is not clear which metal of the three metal system has peroxidase properties. According to these studies, this kind of $\mathrm{PdCuAu}$ NPs-based sensor has a promising prospect in the biological chemistry.

\section{DATA AVAILABILITY STATEMENT}

All datasets generated for this study are included in the article/Supplementary Material.

\section{AUTHOR CONTRIBUTIONS}

FN, LG, JA, and YW conceived and carried out experiments, analyzed data, and wrote the paper. All authors read and approved the final manuscript.

\section{FUNDING}

This work was supported by the National Natural Science Foundation of China (Grant no. 21864020), the Natural Science Foundation of Inner Mongolia (Grant no. 2018MS02012), Collaborative Innovation Center for Water Environmental Security of Inner Mongolia Autonomous Region, China, (Grant no. XTCX003), Young Science and Technology Talents Program (Leading Person) in Inner Mongolia Autonomous Region Colleges and Universities (Grant no. NJYT-19-A04).

\section{SUPPLEMENTARY MATERIAL}

The Supplementary Material for this article can be found online at: https://www.frontiersin.org/articles/10.3389/fchem. 2020.00244/full\#supplementary-material

Ge, J., Yang, X., Luo, J., Ma, J., Zou, Y., Li, J., et al. (2019). Ordered mesoporous $\mathrm{CoO} / \mathrm{CeO} 2$ heterostructures with highly crystallized walls and enhanced peroxidase-like bioactivity. Appl. Mater. Today 15, 482-493. doi: 10.1016/j.apmt.2019.03.009

Guo, J., Wang, Y., and Zhao, M. (2018). 3D flower-like ferrous(II) phosphate nanostructures as peroxidase mimetics for sensitive colorimetric detection of hydrogen peroxide and glucose at nanomolar level. Talanta 182, 230-240. doi: 10.1016/j.talanta.2018.01.080

Guo, S., Zhang, X., Zhu, W., He, K., Su, D., Mendoza-Garcia, A., et al. (2014). Nanocatalyst superior to $\mathrm{Pt}$ for oxygen reduction reactions: the case of core/shell Ag(Au)/CuPd nanoparticles. J. Am. Chem. Soc. 136, 15026-15033. doi: $10.1021 /$ ja508256g

Han, L., Zeng, L., Wei, M., Li, C., and Liu, A. (2015). Mesoporous carbon composite with novel per-oxidase-like activity towards glucose colorimetric assay. Nano 7, 11678-11685. doi: 10.1039/C5NR0 2694F

Hu, A. L., Liu, Y. H., Deng, H. H., Hong, G. L., Liu, A. L., Lin, X. H., et al. (2014). Fluorescent hydrogen peroxide sensor based on cupric oxide nanoparticles and its application for glucose and L-lactate detection. Biosens. Bioelectron. 61, 374-378. doi: 10.1016/j.bios.2014.05.048

Huang, X. Q., Zhao, Z. P., Chen, Y., Zhu, E. B., Li, M. F., Duan, X. F., et al. (2014). A rational design of carbon-supported dispersive Pt-based octahedra as efficient oxygen reduction reaction catalysts. Energy Environ. Sci. 7, 2957-2962. doi: 10.1039/C4EE01082E

Hwang, S. J., Yoo, S. J., Jang, S., Lim, T.-H., Hong, S. A., and Kim, S.-K. (2011). Ternary Pt-Fe-Co alloy electrocatalysts prepared by electrodeposition: 
elucidating the roles of $\mathrm{Fe}$ and $\mathrm{Co}$ in the oxygen reduction reaction. J. Phys. Chem. C 115, 2483-2488. doi: 10.1021/jp106947q

Jiang, G., Zhu, H., Zhang, X., Shen, B., Wu, L., Zhang, S., et al. (2015). Core/Shell face-centered tetragonal FePd/Pd nanoparticles as an efficient nonPt catalyst for the oxygen reduction reaction. ACS Nano 9, 11014-11022. doi: 10.1021/acsnano.5b04361

Jiang, K., Wang, P., Guo, S., Zhang, X., Shen, X., Lu, G., et al. (2016). Ordered PdCu-based nanoparticles as bifunctional oxygen-reduction and ethanol-oxidation electrocatalysts. Angew. Chem. Int. Ed. 55, 9030-9035. doi: 10.1002/anie.201603022

Jiang, K., Wu, J., Wu, Q., Wang, X., Wang, C., and Li, Y. (2017). Stable fluorescence of green-emitting carbon nanodots as a potential nanothermometer in biological media. Part. Part. Syst. Charact. 34:1600197. doi: 10.1002/ppsc.201600197

Jin, L., Meng, Z., Zhang, Y., Cai, S., Zhang, Z., Li, C., et al. (2017). Ultrasmall Pt nanoclusters as robust peroxidase mimics for colorimetric detection of glucose in human serum. ACS Appl. Mater. Interfaces 9, 10027-10033. doi: $10.1021 /$ acsami.7b01616

Khan, M., Yousaf, A. B., Chen, M. M., Wei, C. S., Wu, X. B., Huang, N. D., et al. (2015). Mixed-phase Pd-Pt bimetallic alloy on graphene oxide with high activity for electrocatalytic applications. J. Power Sources 282, 520-528. doi: 10.1016/j.jpowsour.2015.02.090

Li C., Wang H., Li Y., Yu H., Yin S., Xue H. et al. (2018). Tri-metallic PtPdAu mesoporous nanoelectrocatalysts. Nanotechnology 29, 255404-255413. doi: $10.1088 / 1361-6528 / a a b b 47$

Li, B. S., and Chan, S. H. (2013). PtFeNi tri-metallic alloy nanoparticles as electrocatalyst for oxygen reduction reaction in proton exchange membrane fuel cells with ultra-low Pt loading. Int. J. Hydrog. Energ. 38, 3338-3345. doi: 10.1016/j.ijhydene.2013.01.049

Liu, Q., Chen, P., Xu, Z., Chen, M., Ding, Y., Yue, K., et al. (2017b). A facile strategy to prepare porphyrin functionalized $\mathrm{ZnS}$ nanoparticles and their peroxidaselike catalyty for colorimetric sensor of hydrogen peroxide and glucose. Sens. Actuat. B Chem. 251, 339-348. doi: 10.1016/j.snb.2017.05.069

Liu, Q., Jia, Q., Zhu, R., Shao, Q., Wang, D., Cui, P., et al. (2014). 5,10,15,20-Tetrakis(4-carboxylphenyl)porphyrin-CdS nanocomposites with intrinsic peroxidase-like activity for glucose colorimetric detection. Mater. Sci. Eng. C 42, 177-184. doi: 10.1016/j.msec.2014.05.019

Liu, Q., Yang, Y., Lv, X., Ding, Y., Zhang, Y., Jing, J., et al. (2017a). One-step synthesis of uniform nanoparticles of porphyrin functionalized ceria with promising peroxidase mimetics for $\mathrm{H}_{2} \mathrm{O}_{2}$ and glucose colorimetric detection. Sens. Actuat. B Chem. 240, 726-734. doi: 10.1016/j.snb.2016.09.049

Liu, Q. Y., Yang, Y. T., Li, H., Zhu, R. R., Shao, Q., Yang, S. G., et al. (2015). $\mathrm{NiO}$ nanoparticles modified with $5,10,15,20$-tetrakis (4-carboxylpheyl)porphyrin: promising peroxidase mimetics for $\mathrm{H}_{2} \mathrm{O}_{2}$ and glucose detection. Biosens. Bioelectron. 64, 147-153. doi: 10.1016/j.bios.2014.08.062

Luo, F., Lin, Y., Zheng, L., Lin, X., and Chi, Y. (2015). Encapsulation of hemin in metal-organic frameworks for catalyzing the chemiluminescence reaction of the $\mathrm{H}_{2} \mathrm{O}_{2}$-Luminol system and detecting glucose in the neutral condition. ACS Appl. Mater. Interfaces 7, 11322-11329. doi: 10.1021/acsami.5b01706

Luo, S., and Shen, P. K. (2017). Concave platinum-copper octopod nanoframes bounded with multiple high-index facets for efficient electrooxidation catalysis. ACS Nano 11, 11946-11953. doi: 10.1021/acsnano.6b04458

Nie, F. R., Ga, L., Ai, J., and Wang, Y. (2018). Synthesis of highly fluorescent $\mathrm{Cu} / \mathrm{Au}$ bimetallic nanoclusters and their application in a temperature sensor and fluorescent probe for chromium(III) ions. RSC Adv. 8, 13708-13713. doi: 10.1039/C8RA02118J

Niu, X., Lan, M., Zhao, H., and Chen, C. (2013). Highly sensitive and selective Nonenzymatic detection of glucose using three-dimensional porous nickel nanostructures. Anal. Chem. 85, 3561-3569. doi: 10.1021/ac3030976

Oemrawsingh, S. S. R., Markešević, N., Gwinn, E. G., Eliel, E. R., and Bouwmeester, D. (2012). Spectral properties of individual DNA-hosted silver nanoclusters at low temperatures. J. Phys. Chem. C 116, 25568-25575. doi: 10.1021/jp307848t

Shan, X. Y., Chai, L. J., Ma, J. J., Qian, Z. S., Chen, J. R., and Feng, H. (2014). B-doped carbon quantum dots as a sensitive fluorescence probefor hydrogenperoxide andglucose detection. Analyst 139, 2322-2325. doi: 10.1039/C3AN02222F

Song, P., Liu, L., Wang, A.-J., Zhang, X., Zhou, S.-Y., and Feng, J.-J. (2015). One-pot synthesis of platinum-palladium-cobalt alloyed nanoflowers with enhanced electrocatalytic activity for ethylene glycol oxidation. Electrochim. Acta. 164, 323-329. doi: 10.1016/j.electacta.2015.02.229

Sriphathoorat, R., Wang, K., Luo, S. P., Tang, M., Du, H. Y., Du, X. W., et al. (2016). Well-defined PtNiCo core-shell nanodendrites with enhanced catalytic performance for methanol oxidation. J. Mater. Chem. A 4, 18015-18021. doi: $10.1039 /$ C6TA07370K

Sun, L., Ding, Y., Jiang, Y., and Liu, Q. (2017). Montmorillonite-loaded ceria nanocomposites with superior peroxidase-like activity for rapid colorimetric detection of $\mathrm{H}_{2} \mathrm{O}_{2}$. Sensor. Actuat. B Chem. 239, 848-856. doi: 10.1016/j.snb.2016.08.094

Tang, M., Luo, S. P., Wang, K., Du, H. Y., Rinrada, S., and Shen, P. K. (2018). Simultaneous formation of trimetallic $\mathrm{Pt}-\mathrm{Ni}-\mathrm{Cu}$ excavated rhombic dodecahedrons with enhanced catalytic performance for the methanol oxidation reaction. Nano Res. 11, 4786-4795. doi: 10.1007/s12274-018-2063-3

Tian, L. L., Chen, Y. L., Wu, S. P., Cai, Y. H., Liu, H. D., Zhang, J., et al. (2017). Onepot synthesis of cubic PtPdCu nanocages with enhanced electrocatalytic activity for reduction of $\mathrm{H}_{2} \mathrm{O}_{2}$. RSC Adv. 7, 34071-34076. doi: 10.1039/C7RA03220J

Wang, C., Lin, H., Xu, Z., Huang, Y., Humphrey, M. G., and Zhang, C. (2016). Tunable carbon-dot-based dual-emission fluorescent nanohybrids for ratiometric optical thermometry in living cells. ACS Appl. Mater. Interfaces 8, 6621-6628. doi: 10.1021/acsami.5b11317

Wang, C., Ling, L., Yao, Y., and Song, Q. (2015). One-step synthesis of fluorescent smart thermo-responsive copper clusters: a potential nanothermometer in living cells. Nano Res. 8, 1975-1986. doi: 10.1007/s12274-015-0707-0

Wang, H. J., Yin, S. L., Li, Y. H., Yu, H. J., Li, C. J., Deng, K., et al. (2018). Onestep fabrication of tri-metallic $\mathrm{PdCuAu}$ nanothorn assemblies as an efficient catalyst for oxygen reduction reaction. J. Mater. Chem. A. 6, 3642-3648. doi: 10.1039/C7TA10342E

Wang, X., Choi, S. I., Roling, L. T., Luo, M., Ma, C., Zhang, L. et al. (2015). Palladium-platinum core-shell icosahedra with substantially enhanced activity and durability towards oxygen reduction. Nat. Commun. 6:7594. doi: $10.1038 /$ ncomms 8594

Wang, Z., von dem Bussche, A., Kabadi, P. K., Kane, A. B., and Hurt, R. H. (2013). Biological and environmental transformations of copper-based nanomaterials. ACS Nano 7, 8715-8727. doi: 10.1021/nn403080y

Wu, M., Meng, S., Wang, Q., Si, W., Huang, W., and Dong, X. (2015). Nickelcobalt oxide decorated three-dimensional graphene as an enzyme mimic for glucose and calcium detection. ACS Appl. Mater. Interfaces 7, 21089-21094. doi: 10.1021/acsami.5b06299

Xia, B. Y., Wu, H. B., Li, N., Yan, Y., Lou, X. W., Wang, X. (2015). One-pot synthesis of Pt-Co alloy nanowire assemblies with tunable composition and enhanced electrocatalytic properties. Angew. Chem., Int. Ed. 54, 3797-3801. doi: $10.1002 /$ anie.201411544

Xu, G.-R., Liu, F.-Y., Liua, Z.-H., and Chen, Y. (2015). Ethanol-tolerant polyethyleneimine functionalized palladium nanowires in alkaline media: the "molecular window gauze" induced the selectivity for the oxygen reduction reaction. J. Mater. Chem. A 3, 21083-21089. doi: 10.1039/C5TA06644A

Xue, Q., Xu, G. R., Mao, R. D., Liu, H. M., Zeng, J. H., Jiang, J. X., et al. (2017). Polyethyleneimine modified AuPd@PdAu alloy nanocrystals as advanced electrocatalysts towards the oxygen reduction reaction. J. Energy Chem. 26, 1153-1159. doi: 10.1016/j.jechem.2017.06.007

Yan, G., Zhang, Y., and Di, W. (2018). An enzymatic reaction mediated glucose sensor activated by $\mathrm{MnO}_{2}$ nanosheets acting as an oxidant and catalyst. Analyst 143, 2915-2922. doi: 10.1039/C8AN0 0657A

Yang, L., Zhang, Q., Cui, Z., Gerboth, M., Zhao, Y., Xu, T. T., et al. (2017). Ballistic phonon penetration depth in amorphous silicon dioxide. Nano Lett. 17, 7218-7225. doi: 10.1021/acs.nanolett.7b02380

Yang, X., Cheng, X., Ma, J., Zou, Y., Luo, W., and Deng, Y. (2019). Large-pore mesoporous $\mathrm{CeO} 2-\mathrm{ZrO} 2$ solid solutions with in-pore confined Pt nanoparticles for enhanced CO oxidation. Small 15:1903058. doi: $10.1002 /$ smll.201903058

Yin, A. X., Min, X. Q., Zhu, W., Liu, W. C., Zhang, Y. W., and Yan, C. H. (2012). Pt-Cu and Pt-Pd-Cu concave nanocubes with high-index facets and superior electrocatalytic activity. Chem. Eur. J. 18, 777-782. doi: 10.1002/chem.201102632

Yousaf, A. B., Imran, M., Uwitonze, N., Zeb, A., Zaidi, S. J., Ansari, T. M., et al. (2017a). High-temperature and high-pressure pyrolysis 
of hexadecane: molecular dynamic simulation based on reactive force field (ReaxFF). J. Phys. Chem. C 121, 2069-2078. doi: 10.1021/acs.jpca.6 12367

Yousaf, A. B., Imran, M., Zaidi, S. J., Kasak, P., Ansari, T. M., Manzoor, S., et al. (2017b). Synergistic effect of interfacial phenomenon on enhancing catalytic performance of $\mathrm{Pd}$ loaded $\mathrm{MnOx}-\mathrm{CeO}_{2}-$ $\mathrm{C}$ hetero-nanostructure for hydrogenation and electrochemical reactions. J. Mater. Chem. A 5, 10704-10712. doi: 10.1039/C7TA0 $2122 \mathrm{D}$

Zhang, L., Chen, M., Jiang, Y., Chen, M., Ding, Y., and Liu, Q. (2017a). A facile preparation of montmo rillonite supported copper sulfide nanocomposites and their application in the detection of $\mathrm{H}_{2} \mathrm{O}_{2}$. Sens. Actuat. B Chem. 239, 28-35. doi: 10.1016/j.snb.2016. 07.168

Zhang, L., Hai, X., Xia, C., Chen, X. W., and Wang, J. H. (2017b). Growth of $\mathrm{CuO}$ nanoneedles on graphene quantum dots as peroxidase mimics for sensitive colorimetric detection of hydrogen peroxide and glucose. Sens. Actuat. B Chem. 248, 374-384. doi: 10.1016/j.snb.2017. 04.011
Zhao, T. T., Chen, Q. Y., and Yang, H. (2015). Spectroscopic study on the formation of DNA-Ag clusters and its application in temperature sensitive vehicles of DOX. Spectrochim. Spectrochim. Acta A Mol. Biomol. Spectrosc. 137, 66-69. doi: 10.1016/j.saa.2014.08.025

Zhou, W. J., Zhu, J. B., Teng, Y., Du, B. J., Han, X., and Dong, S. J. (2018). Novel dual fluorescence temperature-sensitive chameleon DNA-templated silver nanocluster pair for intracellular thermometry. Nano Res. 11, 2012-2023. doi: $10.1007 /$ s12274-017-1817-7

Conflict of Interest: The authors declare that the research was conducted in the absence of any commercial or financial relationships that could be construed as a potential conflict of interest.

Copyright $\odot 2020 \mathrm{Nie}, \mathrm{Ga}, \mathrm{Ai}$ and Wang. This is an open-access article distributed under the terms of the Creative Commons Attribution License (CC BY). The use, distribution or reproduction in other forums is permitted, provided the original author(s) and the copyright owner(s) are credited and that the original publication in this journal is cited, in accordance with accepted academic practice. No use, distribution or reproduction is permitted which does not comply with these terms. 